(C) ACM, 2017. This is the author's version of the work. It is posted here by permission of ACM for your personal use. Not for redistribution. The definitive version was published in Proceedings of the 2017 International Conference on Computer Science and Artificial Intelligence, ISBN: 978-1-4503-5392-2, DOI: 10.1145/3168390.3168443

\title{
Understanding subjective aspects in the use of human computer interface for government Information System: A reflexive analysis
}

\author{
Nayeth I. Solorzano Alcivar \\ Escuela Superior Politecnica del \\ Litoral (ESPOL) \\ Km 30.5 Via Perimetral \\ Guayaquil - Ecuador \\ +594979558325 \\ nsolorza@espol.edu.ec
}

\author{
Luke Houghton \\ Griffith University \\ Nathan Campus \\ Brisbane - Australia \\ +6143 . \\ I.houghton@griffith.edu.au
}

\author{
Louis Sanzogni \\ Griffith University \\ Nathan Campus \\ Brisbane - Australia \\ $+614 \ldots$ \\ I.sanzogni@griffith.edu.au
}

\begin{abstract}
Computer application users continue to argue that system developers are still not paying enough attention to making their products easier to use or "user-friendly." However, system developers might argue that the human computer interface (HCI) used for their systems are carefully designed and developed. They would also argue that the request for the services that an information system can provide normally outdrive the demand for 'ease-of-use'.. In spite of other aspects, that might change the attitude toward usage behavior. This directly influences the successful adoption of an Information Systems (IS). This paper presents a summary of the outcomes of a mix-method study proposing an adapted theory that empirically supported the identification of three main group of aspects affecting IS adoption in the public organizations of emerging countries. Public Ecuadorian organization is used as the analysis case. Using a reflexive analysis, we highlight in this article the effect of the subjective aspects such as Perceived Ease of Use, Perceived Usefulness directly affecting Attitudes Toward Using and Usage Behaviour as critical factors influencing successful information system adoption (SISA) in specific local contexts. Therefore, the cautious design of human computer interfaces, must be the considered when developing an IS for public organizations due to their direct impact on attitude toward using and usage behaviour on SISA.
\end{abstract}

\section{CCS Concepts}

- Information systems $\rightarrow$ Information system applications. Human-centered computing $\rightarrow$ Human computer interaction (HCI) $\rightarrow$ Design and evaluation methods $\rightarrow$ User studies, Field studies.

\section{Keywords}

Human-computer interaction (HCI); Human-computer interface (HCI); human-system interface (HSI); Information System, Ease of Use, Usefulness Perception, Attitude Toward Using, Usage Behaviour; Public Organizations, merging Economies; Ecuador

\section{INTRODUCTION}

Human-computer interaction (HCI) is known as the study of how people interact with computers systems [1, 2]. This ncludes all related applications and devices. It also includes howthese interactions influence work and activity [1] on usage behavior, human-system interface (HSI), human-machine interface (HMI), and man-machine interface (MMI).aBooth [2] argues that a name (HCI) it does not do justice to the complexity and the multidisciplinary nature of the subject matter. It is also known that the HCI studies examine to what extent a computer system and its components are, or are not, developed for successful interaction with human beings. Historically, most of the computer systems developers have not paid much attention, for example, to the perception of ease-of-use and usefulness identified as relevant factors of user technology acceptance and system adoption [3-6]. On the other hand, computer scientists have recently claimed or are aware that these perceptions could be defined precisely and measured as part of the subjective aspects, empirically evidenced for decades, on behavioural research related to technology adoption [7]. Furthermore, there are alack of studies analysing how users use and adopt the information systems and related computer technology applications [8], in pubic organizations of emerging economies.

The purpose of this article is to understand the subjective aspects of HCI including: perception of Usefulness and Ease of Use associated, Attitude and Usage behavior in local public organizations. This is among other factors identified as main drivers of SISA.

This was derived from a large mixed-method study undertaken to identify factors affecting IS adoption in local public organizations. This article only summarizes the outcomes of the research process followed to identify the most relevant factors affecting adoption. Then, it concentrates the analysis and discussion on how to handle the subjective aspects identified as direct factors impacting user behavior, prior to implement an IS in an organization, as this could help the understanding of Information Technology (IT) and IS acceptance, for minimising underutiliation or eventual abandonment of systems [8] implemented or to be developed.

\section{THE MIXED-METHOD STUDY BACKGROUND}

The aim of this researchis to identify the most prominent candidate drivers of SISA in public organizations of emerging economy, particularly in Latin America (LAT), a large mix-method study was undertaken. Public Ecuadorian Organizations (PEOs) was the focus case. It is believed that this area of study is important because the majority of research in this field overlooks emerging economies.

Numerous IS/IT adoption studies are based on empirically supported theories grounded on factors explaining variances of 
technology acceptance and/or software or system usage at the individual and organizational level ( see for example Davis [3, 4], Venkatesh and Davis [5], Rogers [9], Tornatzky, Fleischer and Chakrabarti [10], and DeLone and McLean [11]). However, most of the empirical evidence is centered on research carried out in countries other than emerging regions, largely omitted in IT/IS development and adoption studies [12, 13]. This is problematic because a clear picture of contextual differences cannot be effectively observed.

From the overall study, firstly we identify existing theories, factors, IS success stories, or software usage that have been associated with the successful adoption of IS in organizations. An analysis of the applicability of the theories to emerging economies then follows. The objective was to homogenize from existing theories factors on adoption studies and determine whether any of the theories, or an adapted theory, can be applied to understand adoption in the context of emerging economies. Then to select a list of sound identified factors to be proposed as the most prominent candidate drivers of SISA in public organizations of emerging economy

The entire pluralistic research was conducted applying a qualitative-quantitative mixed-method. Three extensive stages were carried out, followed a Qualitative Comparative Analysis (QCA). Finally, a reflexive analysis was applied to the identified factors clustered by aspects. The research methodology was developed as follows:

Stage 1- A Systematic Literature Review (SLR) process to analyse existing literature related to the discipline was carried out.

Stage 2- Hermeneutic phenomenology process to analyses and interpret local secondary data related to LAT and Ecuador was undertaken. The data collected included White and Green papers, government reports, information from government web sites, and local related news.

Stage 3- Transcendental Phenomenology and Hermeneutic circles processes for the analysis of local expert and practitioner interview transcripts, respectively. The data collected came from local experts and practitioners working in Public Ecuadorian Organizations

The QCA process- The initial findings obtained from the three stages were refined by using Fuzzy Qualitative Comparative Analysis (fs/QCA) as a mechanism bridging qualitativequantitative methods (Hollstein \& Wagemann, 2012). From this process, a refined list of 14 candidate drivers of SISA in PEOs was obtained.

Reflexive Analysis- the identified factors selected, clustered by similar aspects, were re-examined based on data analysed in previous stages to conceptualise and explain relationships identified between them. From this analysis, propositions and hypotheses were stated and the adapted theory developed as a SISA model was obtained.

Finally, for this article, we concentrated the analysis and discussion on how to handle perceived factors, impacting user behavior on SISA. This helped to the understandi the subjective aspects associated with the use of human computer interfaces for information systems adopted in public organizations of emerging economies. Further studies also are recommended at the end of this paper.

\section{THE DATA EXTRATION AND ANALYSIS PROCCESSES}

\subsection{An Overview of the Processes}

Data related to the current research were collected and analysed from different sources and in different stages. Initially, by gathering information from an SLR process. At this stage, the purpose was to identify existing theories, and proposed drivers explaining IT/IS acceptance, and software usage that have been associated with the successful adoption of IS in organizations. As a result, 11 Theories and models were identified as seminal theories such as TRA, SCT, TAM, DOI, TPB, DOI, and MT, used in a variety of IS/IT studies related to adoption studies in developed countries (see Table 1). From this list, it was noted that several developing countries' adoption studies propose the use of hybrid models supported by the identified theories such as TAM2, UTAUT, D\&M-ISS, DOI, and TOE. However, in localised studies focused on developing countries, they proposed to adopt their own model but mention these theories as referral support. These results gave the researcher an insight that the possible applicability of using any of these theories to measure SISA in PEO contexts needed to be strengthened by continued analysis.

Table 1. The Most Common Theories/Models Used in IS Adoption Studies

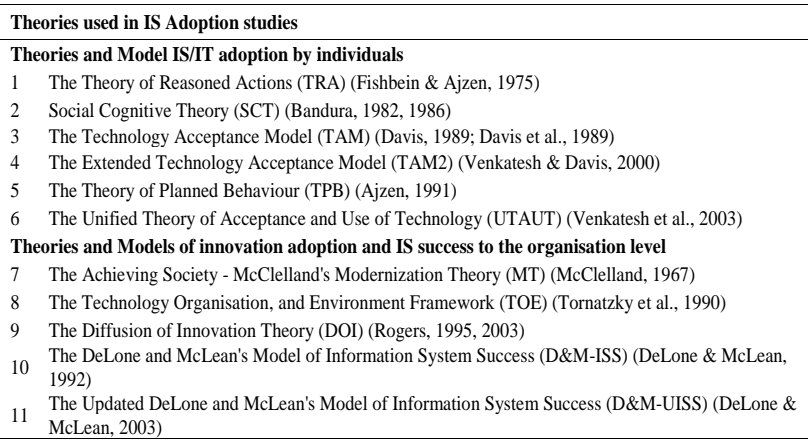

On the other hand, by following a Phenomenological approach and using NVivo as a tool for the data analysis process, a widespread number of items (named as factors, constructs, drivers, and so on) that were proposed, suggested, or implied as possible drivers affecting IS/IT adoption or IS success, were noted. All these items were highlighted as open codes. In continuing processes, the identified open codes were classified, grouped, and re-grouped (by similar names, meanings, related significance, or definitions) until a final set of 50 themes was obtained.

In the analysis process of each stage and summarized at the end of stage $3 \mathrm{~B}$ (see Table 1), the researcher considered the need to organise the identified themes as Control Characteristics groups, clustered them by similar aspects as follows:

Subjective Aspects groups all the formed themes related to subjective features of social perceptions (Social control characteristics) as well as behaviour and perceptions related to the individuals (knowing that individuals are responsible for managing the organisations and using the systems). Features such as behaviour, attitude, perceptions, subjective norms, and motivations are considered Subjective Aspects, incorporating the selected themes clustered in this group. 
Technological Aspects groups the themes formed by a variety of characteristics related to the features of computerised systems and the infrastructure involved for developing, implementing, and using technological applications associated with the adoption of IS.

Public Aspects includes all themes related to national and organisational characteristics. This involves determined external environment features, such as culture, politics, policies and regulations, government orientation, and the different organisational features.

Demographic Aspects groups themes linked to characteristics about the target of the population researched, such as age, gender, education, and income. This helps to assemble data about specific characteristics of the population, if required.

National Economic Aspects groups themes involved with characteristics related to economic activities of a society such as economic growth, income level, or economic climate. This aspect, for example, is currently used as a fact determinant of the development of knowledge society [14].

Industry and Market Aspects groups the themes related to characteristics that involve a broad range of issues about environment, dynamics, and attractiveness of special markets in determined industries, such as market structure, competition, and labour force, among others.

Continually, a QCA technique was applied to complete the selection process. To complete the research, process a reflexive analysis was undertaken to analyse the relationship between themes selected as the most feasible candidate drivers of SISA. This helps to finally state the research propositions and hypotheses.

\subsection{The Partial Outcomes by Stage Process}

In the SLR process, from 28 studies selected, an initial set of open codes, grouped in 60 themes and clustered by similar aspects, was obtained (Table 1). This process was identified as Stage 1 of the current study. In Stage 2, using a Hermeneutical process, secondary data collected from 34 LAT sources, were examined and a second set of 52 themes also clustered by similar aspects was obtained (Table 1). Stage 3 was divided in two parts (A and B). In Stage 3A, from 10 local experts interviewed in PEOs, a third set of 76 themes again grouped by aspects was formed (Table 1). Afterwards, all three sets of themes identified were compiled, continually refined. This process, as Stage 3B, was complemented with an analysis of 45 on-site semi-structured interviews carried out in public Ecuadorian organisations (Table 4). This ongoing coding process continued until saturation was reached. As a result, a restructured set of 50 themes including the percentage of level of references identified by stage was obtained.
Table 1. Finding Summary per Process

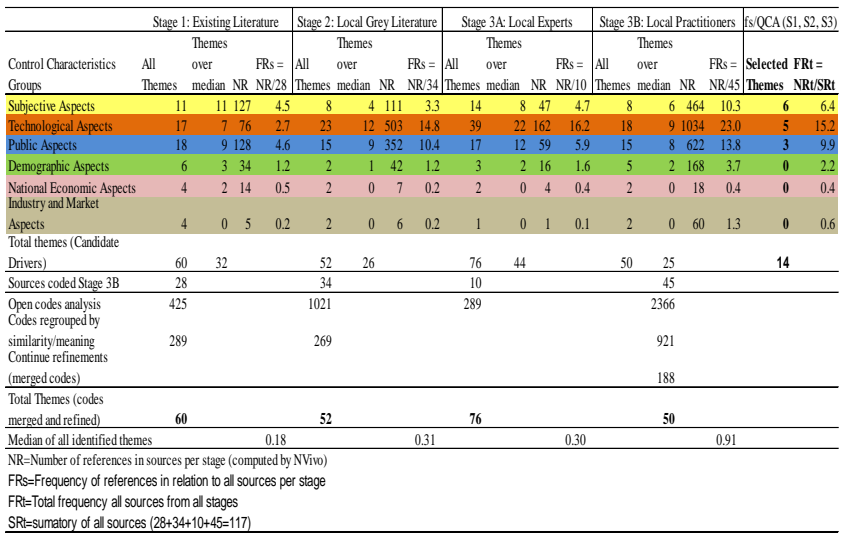

Furthermore, by highlighting the number of most referenced themes, it was noted that 25 themes over a refined set 50 themes obtained at the end of Stage 3B were identified over the frequency of references median. Clustered by Subjective Aspects, it was noted that most of the themes linked to this group, 6 out of 8 themes were identified over the FR median. Grouped by Technological Aspects, 9 of 18 themes were identified over the FR median obtained. In the Public Aspect group, 8 out of 15 themes were identified over the FR median. In this Demographic Aspects group, 2 out of 5 themes were identified over the FR median obtained. In the National and Economic Aspects group nine out of 2 themes were identified over the FR median obtained. The same as Industry and Market Aspects group (see Table 1). Tu sum up, Technological and Subjective Aspects with a distribution over the 36\% and 32\% of the distribution encloses the major number of themes identified as relevant by existing literature and analysing primary data in local contexts. This was followed by themes grouped in Public Aspects with 24\%, and then Demographic Aspects with only an $8 \%$. Themes linked to National and Economic Aspects, and Industry and Market Aspects were not substantially mentioned as relevant. (Figure 2).

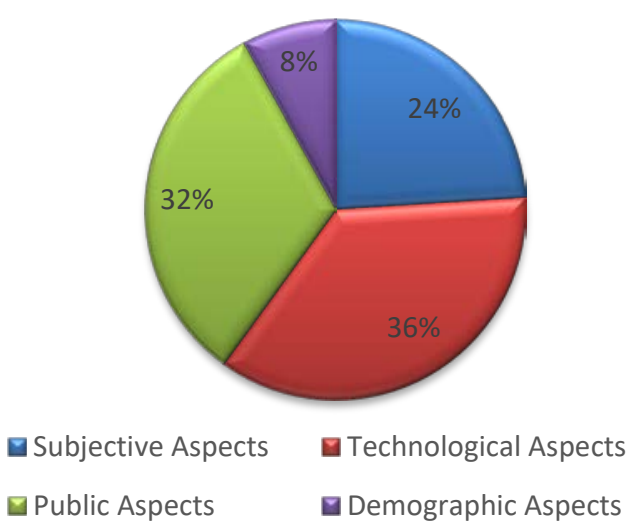

Figure 1. Identification of Themes Over the Media Clustered by Aspects. 


\subsection{Applying QCA to refine the themes' Selection}

From the three previous stages, a set of 50 formed themes, and the distribution of minimum and maximum percentages of references by stage was obtained (defined as FrR). However, these outcomes were considered not sufficient to determine which of the 50 themes should be selected as drivers of SISA in LAT organisational contexts. Therefore, the analysis process was complemented with a QCA mechanism for a final refining selection of themes as candidate factors of SISA.

QCA as a comparative analysis strategy was applied to reveal patterns of association across the set of formed themes and to provide support for the existence of causal relations between determined conditions (Stage 1, Stage 2, and Stage 3) in relation to specific cases (each theme is considered a case) [15]. By using a Fuzzy QCA (fs/QCA) computer application, 14 themes with the higher level of relevance and their relationship within the three stages were identified. As a result, six of the themes selectedAccessibility-Interconnectivity (ACIN); Regulation \& Policies (REPO); Information Availability (INAV); Perceived Usefulness (PEUS); Attitude Towards Using - Intention to Use (ATUI); and Usage Behaviour and Use (USBU) - were identified as the most relevant themes. All of them determined the necessity condition for SISA outcomes (see Figure 2). From them, PEUS was determined as the core theme relevant for all the sources [16]. The remaining eight themes-Cultural \& Values Aspects (CUVA), Nature of Development (NADE), Trust \& Leadership Governance (TRLG), Technology Infrastructure (TEIN), Net Benefits Perception (NEBP), Perceived Ease of Use (PEOU), Subjective Norms \& Motivation (SNMO) and System Development \& Implementation (SYDI) - were identified as highly important, but only in one of the three stages at a time. These were recognised as the Inus condition. These mixed results were then anticipated as the sufficiency condition (see Figure 2) to determine the final themes nominated as candidate drivers of SISA in public LAT organisations, and to be proposed for further studies.

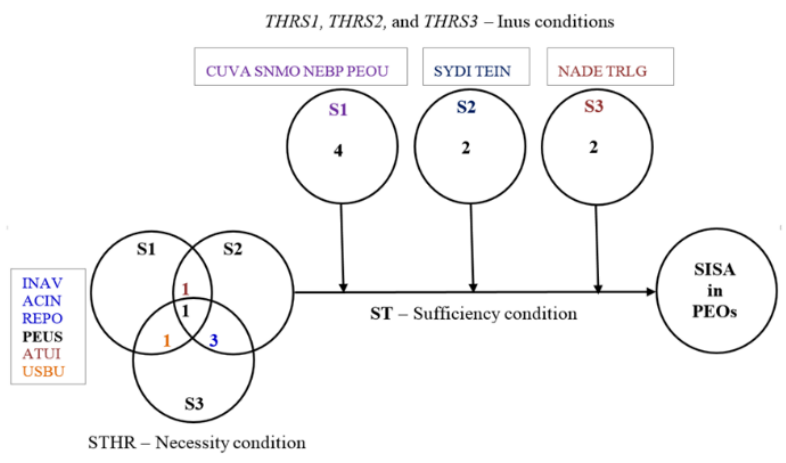

Figure 2. Relationships forming a sufficiency condition of the selected themes. Source [16]

To determine the nature of the themes and to better examine their influence as candidate drivers of SISA in LAT, also they were clustered Aspect. To this end, the Control Characteristics group previously determined was used. Thus, the selected themes were examined and reorganised into groups in which the selected themes were clustered; namely, Subjective Aspects, Technological Aspects, and Public Aspects (see Figure 3), from which the most relevant Themes as the most feasible candidate drivers of SISA were obtained.

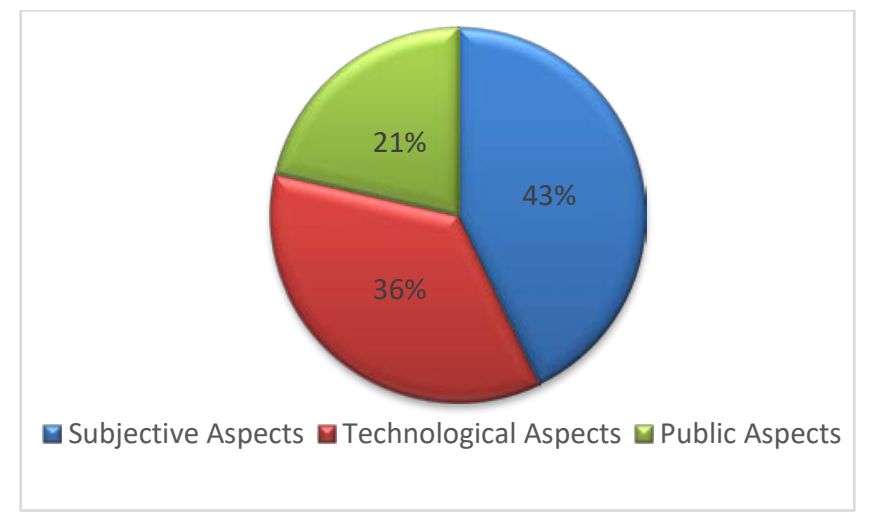

Figure 3. Distribution of 14 Themes Select by Aspects

Subjective Aspects- From this group, six themes out of 14 themes are largest number of candidate drivers (representing the $43 \%$ of the selection group) selected as significant based on the QCA process. These are Perceived Usefulness (PEUS), Subjective Norms and Motivations (SNMO), Attitude Towards Using Intention to Use (ATUI), Perceived Ease of Use (PEOU), Usage Behaviour and Use(USBU), and Net Benefits Perception (NEBP). All of them highly empirically supported in many of the identified theories related to IT/IS acceptance. PEUS was the only theme evidencing high significance in the three previous stages.

Technological Aspects- Six out of 14 themes were selected from this group (representing $36 \%$ of the selection). These are, Information Availability (INAV), Accessibility-Interconnectivity (ACIN), System Development and Implementation (SYDI), Technology Infrastructure (TEIN) and Nature of Development (NADE). From these themes, ACIN and INAV were identified as the most relevant from the sources analysed, particularly in Stage 2. Moreover, INAV, and SYDI, are emerging themes from local sources (identified in Stage 2 and 3), which means they were not previously proposed as drivers of IS adoption in the existing theories reviewed.

Public Aspects- Within this group, three out of 14 themes were identified as relevant (representing $21 \%$ of the selection process). These are, Regulation \& Policies (REPO), Cultural \& Values Aspects (CUVA), and Trust and Leadership Governance (TRLG). From these group, REPO was identified as highly significant in Stage 2 and 3 but also mentioned in Stage 1. (Figure 3)

\section{THE PROPOSED ADAPTED THEORY}

Applying an inductive approach, using a reflexive analysis, the data coded by NVivo was again analysed bottom-up to build the patterns for the themes identified [17]. From this process, the operational definition of each theme was developed and the research validations were elucidated based on exemplary key references quoted from S1 and quotes analysed from local sources in S2 and S3. Short exemplary (best example) tables were included to give a close view of the references and opinions supporting the relationship propositions and hypotheses stated linked to the identified themes. The definition and the research validation for the 14 themes selected as strong candidate drivers of SISA were determined (see Figure 4). 
Research propositions were determined, and hypotheses stated. The development of an adapted theory viewed as a model was finally developed. This model illustrates the proposed relationship anticipated between the final set of candidate drivers affecting SISA in PEOs (see Figure 4). Nevertheless, the model is expected to be tested in future quantitativestudies recommended to be undertaken in local public organisations of LAT economies, due to cultural similarities and the low level of technology readiness identified in all of them as common aspects.

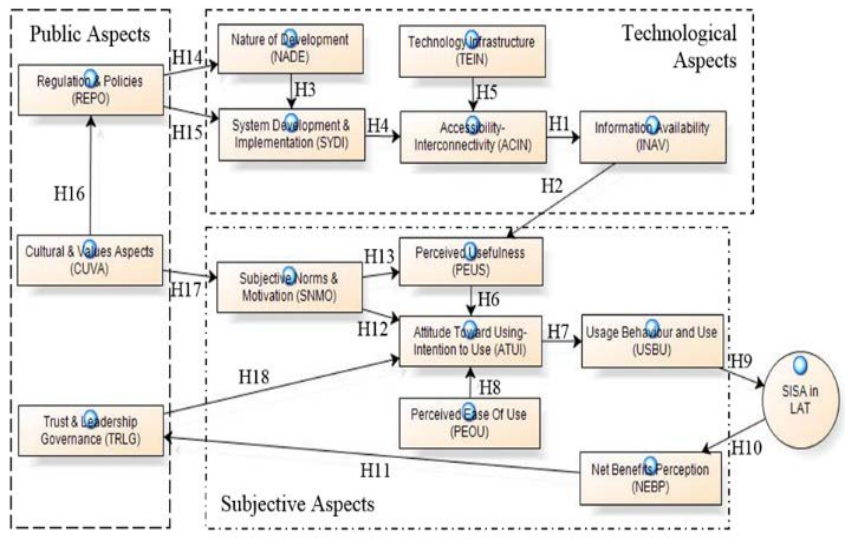

Figure 4. The proposed Adapted theory - SISA Model for LAT contexts

Even though at the aims of the overall study is to propose and adapted theory explaining research propositions between Subjective, Technological and Public Aspects (see Figure 4), this section following section of the paper is concentrated on a reflexive analysis focusing the need of the understanding the PEUS and PEOU as factors identified that moderate ATUI and USBU to guarantee SISA. A reflexive final analysis was carried out to firm definitions and research validations for the proposed themes as strong candidate factors of SISA. The relationships between the specific factors to be analysed and how they possibly influence SISA local contexts are determined through supporting examples.

\section{A REFLEXIVE ANALYSIS AND DISCUSSION OF SUBJECTIVE ASPECTS}

Aiming to understand subjective aspect relationship in the proposed model and despite of the need of accentuate SISA in Public organizations, most of studies have emphasize more on the technical aspect of computer system application to be implemented and the possible inclusion of public aspects such as REPO. User users' perception of the technology have been ignoring in the development of algorithms [8] required for example as part of the design for a SYDI planning. Furthermore, there has been scarcity of study analysing how users use the technology $[8,17]$. Therefore, it is important to understand subjective aspects affecting user behaviour to this case factors such as PEOU and PEUS, mostly related to HSI or HCI prior to implement an IS for local public institutions, as this could help minimising its underutilisation or eventual abandonment [8].

By considering that current findings of this study to identify candidate drivers of SISA in local context, it has been evidenced the need of paying special attention to user perception factors, mostly clustered as Subjective Aspects. Most of these factors identified, have been empirically proposed to explain IS/IT acceptance and usage, in existing theories such as TAM, TAM2,
UTAUT, D\&M-ISS, DOI, and TOE. From them, PEOU and PEUS are supported as direct determine of ATUI to moderate USBU are explained in this reflexive analysis to evidence the need of to the use HSI for adopting an IS in public organizations.

\subsection{Perceived Usefulness -PEUS.}

PEUS is defined as "The degree to which a person believes that using the system will enhance his or her job performance” Davis [3] within an organisational context. The users may want to accomplish an activity because it is perceived to be instrumental in attaining valued outcomes such as improved job performance or pay, or promotion.

\section{Research validation of PEUS}

PEUS is the theme most frequently mentioned in the sources analysed in the three stages of the current study (S1, S2 and S3) (see Table 7.3). It is significant because PEUS is proposed by several theories used to explain IS/IT adoption as a determinant of the Attitude Towards Using or the Intention to Use (ATUI) a system. This is supported, for example, by TAM [3] and TAM2 [4]. The PEUS is the degree to which users believe that using some systems will increase their job performance in their working environment [3, 18]. Furthermore, PEUS motivates users to accomplish an activity as instrumental in achieving value outcomes due to the influence of Subjective Norms and Individual Motivations -SNMO [4]. Moreover, from the analysis of local documents and interviews, it was noted that the individual PEUS of a system is also influenced by INAV as an instrument to achieve some outcomes necessary to succeed in IS adoption. The reflexive analysis in all cases was extracted from exemplary quotes obtained from the transcript and the literature reviewed.

Overall, PEUS is suggested as one of the strongest drivers of SISA in local public organisations, influenced by INAV and SNMO and positively affecting ATUI.

\subsection{Attitude Towards Using - Intention to Use -ATUI}

ATUI is defined as the individual's general feeling of favourableness or unfavourableness toward the use of an information system [Ajzen and Fishbein, 1972 as cited in 18]. The organisations and their employees can have a positive attitude or can demonstrate resistance to changes in relation to the use of an IS.

\section{Research validation of ATUI}

ATUI is one of the most referenced themes identified from the sources of the three stages analysed. It is particularly proposed in $\mathrm{S} 1$ and referred to or implied from the sources analysed in S2; nevertheless, interviewees from S3 also mentioned these themes. In S1, ATUI is assumed to be motivational aspects that impact behaviour; thus, it is supported as a determinant of the Usage Behaviour and Use-USBU of any system [3, 4, 19]. In S2 it was apparent that responsible ATUI is suggested as a positive fact in determining local IS/ICT REPO. In S3, ATUI is also mentioned by interviewees highlighting the resistant approach that some users can demonstrate under mandatory conditions. It also reinforces that the more positive the attitude toward using a system, the more easily the behavioural intention to use a system can be determined.

Overall, ATUI is assumed to be a candidate driver of SISA in local public organisations. It can be implied that the more positive the 
ATUI of the user in a local public organisation, the higher the probability of corresponding usage behaviour (USBU).

\subsection{Perceived Ease of Use -PEOU}

PEOU is defined as the degree to which a system, website, or any technology application is regarded as easy or difficult to understand, operate, and use. In other words, it refers to the degree to which an individual believes that a given technology would reduce job intensity [3]. In local contexts, any IS application perceived as easy to use is also known as "User-friendly".

\section{Research validation of PEOU}

PEOU is a referenced theme identified from the sources of the three stages executed in this study. However, it is most frequently proposed in the literature analysed in S1. In S1 sources, PEOU is identified as the degree of "ease" associated with the use of the system, or how free of effort using a system would be [3, 20, 21]. Theoretical studies of IS adoption PEOU are also proposed as a determinant of the ATUI of a system [3, 4, 6]. From S2 it is implied that public organisations should note that the systems and programs must be "friendly" in order to address the attitude of the users. In S3, PEOU is mentioned by interviewees emphasising that if the use of the system implies less effort, or if it is "user-friendly", then it is used more and people do not get frustrated when they use it.

In summary, PEOU is suggested as a candidate driver of SISA in a local public organisation context. Also, it is implied that if the PEOU of a system is positively identified by the users, they will feel comfortable using it and therefore, the ATUI will be also positive.

\subsection{Usage Behaviour and Use -USBU}

The definition of USBU related to the acceptance of an IS specifies how people are willing to try or how much effort they are planning to exert to use a system [6, 22]. It reflects the general disposition and individual's performance of a specific behaviour accomplished with the intention to achieve an action. In other words, USBU is related to the effort of the individuals and how fast they use technology (in this study technology refers to IS) once they have learned about it [23]. The "use" of a system is considered separate from the intention to use, since “... 'intention' to use is an attitude, whereas 'use' is a behaviour" [11]. Thus, in this research Usage Behaviour and Use was determined as a joint theme, named USBU.

\section{Research validation of USBU}

USBU is one of the relevant referenced themes identified from the sources of the two stages analysed. It is frequently proposed and mentioned in the sources analysed in S1 and S3. From S1 sources, USBU is related to the acceptance of an IS and, considering the effect of external variables such as system characteristics, development process, and training, is jointly determined by the influence of the individual's attitude towards using a system (ATUI) and its perceived usefulness (PEUS). From them, ATUI is considered as having a direct influence on USBU [3-5]. In fact, a specific behaviour usage is generally measured by the intention of achieving an action of using new technology or a determined system [19, 24]. In S3, USBU is mentioned by interviewees as a key to the success of the acceptance of a system. They claim that if a user has to use a system, or if the system is in place and it works and everybody uses it, then its adoption can be considered successful. It is implied that IS adoption only works if people use the actual systems adopted by the organisation, which may allow that the net benefit or the net benefit perception (NEBP) of using a system in a government institution can be determined.

Overall, it is suggested that the continuity of USBU can enable SISA as a direct driver in local public organisations. USBU can be positively influenced by ATUI. In fact, once an IS is adopted by the organisation, its constant usage is assumed as successful IS adoption (SISA).

\subsection{Net Benefits Perception -NEBP}

NEBP refers to the user-perceived advantage evaluation as the tangibility results of using a specific IS. It also can be defined as a relative advantage in relation to the degree to which using an actual system is perceived as being better than using its precursor [6, 9]. This is considering that different users may have a different perception as to what constitutes a benefit to them in relation to the usage of determined IS [11, 25]. In this research, NEBP groups all the positive impacts of using current system measures into a single theme.

\section{Research validation of NEBP}

NEBP is an important referenced theme identified from the sources of the three stages analysed. However, it is frequently proposed as a driver of system adoption in the literature analysed in S1. From the sources of S1, it is apparent that NEBP consolidates different categories of IS impact measures such as work group impact, interorganisational impact, industry impact, consumer impact, and social impact. It is stated that "net benefit" is a simple variable used to combine all the organisational and individual positive impacts, but taking into consideration what will be considered as a benefit, and for whom, at the analysis level (organisational or individual perspective), about whose interest the actual system IS is evaluating. Net benefit is, perhaps, the most accurate descriptor of the final success variable (DeLone $\&$ McLean, 2003). As a relative advantage of using an actual system, NEBP is identified as the degree to which using a system innovation is perceived as better than using a previous version. NEBP, therefore, is considered the most accurate descriptor of the final success of adopting an IS, depending on the relationship between USBU and how positively results are perceived. From S2 and S3, it is implied that in public organisations the NEBP of adopting an actual system is a way to effectively interact with citizens or any users by saving time and money, and helping to find accurate solutions on time. This is particularly relevant to local government leaders and managers of public organisations. The NEBP seems to encourage leaders' commitment with IS adoption that helps to build their trust and leadership governance (TRLG).

To sum up, NEBP can be identified by the positive results of the continued use of a determined IS implemented in a public organisation that is determined as the SISA (focus of this research). At the same time, SISA can enable the NEBP with regard to whose interest the actual system IS is evaluating. The NEBP experienced particularly by leaders may enable TRLG that influence ATUI of using the system.

\subsection{Subjective Norms and Motivations - SNMO}

SNMO explains how people live and work within a cultural environment in which determined values, norms, attitudes, and practices are more or less dominant and work as shared sources of socialisation and social control to achieve something [26]. SNMO 
is a social force to encourage system usage, which is perceived to enhance their status or image in their social system [5, 24, 27].

\section{Research validation of SNMO}

SNMO is an important referenced theme identified from the sources of the three stages analysed. In particular, it is frequently proposed as a driver of system adoption from the literature analysed in S1. From S1 it was noted that several authors supporting IS/IT adoption studies propose SNMO as a social force from which the use of an innovation is perceived to enhance their image or status in their social system. SNMO is related to user characteristics associated with personal belief or external motivation influencing PEUS and (ATUI) [5, 28]. SNMO is linked to the individual's need to comply with other expectations if the individual cares about what other people think about how they act in accordance with a determined behaviour. The more strongly these needs are experienced, the greater the ATUI and, indirectly, USBU will be realised [29]. SNMO is also associated with how individuals' work and lives are influenced by cultural characteristics such as cultural values -CUVA, norms, and practices that serve as shared sources of socialisation and social control [26]. Findings from S2 and S3 demonstrated that public organisation stakeholders believe that the staff is motivated when they are involved in the process of whatever system is implemented. Interviewees hold that users feel empowered and somehow important when they feel involved; for example, by offering some ideas, so that they can be more open to adopting the system once it is in place. Systems empowered by motivated users can moderate ATUI and, somehow, PEUS positively.

Generally speaking, it is suggested that SNMO can be determined as an indirect driver of SISA in local public organisations. The positive direct effect of SNMO may influence ATUI and PEUS positively and can be influenced by CUVA.

\section{THE APPLICABILITY OF HCI/HSI ON SUBJECTIVE ASPECT OF A SISA MODEL}

Studies have successfully used hybrid or extended adapted theories that includ proposed factors as determinants of the Technology Acceptance Model -TAM for predicting and explaining individual IT/IS acceptance based on the subjective psychological beliefs of the individual users. TAM proposes two important determinants to analyses that cause users to accept or reject new technology: perceived usefulness -PEUS and perceived ease of use-PEOU [3-6, 8]. TAM was later extended to TAM2 and developed into UTAUT. Many other variants exist as models for improving the classification of adoption of new technology. However, this study focuses on the SISA model (a proposed adapted theory) which aims to give a new, in-depth insight for explaining the government acceptance of information systems for users inemerging economies.

SISA as an integrated model (adapted from several existing models and new insights) The model integrates PEUS and PEOU in a hypothesis indicating that they influence the attitude of users ATUI, but both factors did not cross-over (see Figure 4). It means that PEUS could not influence PEOU and vice versa. The idea of separation is due to the perception of usefulness. This is an outcome of SNMO which may involve, for example, determined norms, and some motivational aspects such as: image, job relevance, output quality and result demonstrability [5]. It should be noted that PEOU is expected to have process-oriented elements facilitated by the HCI or HSI, such as computer self-efficacy, facilitating conditions, computer anxiety and computer interaction $[6,8]$. Although we have suggested 14 candidate factors that could be included into the model to explain SISA, only the six factors clustered as Subjective Aspects were discussed in this paper. From them four specific factors PEOUS, PEOU, ATUI and USBU are chosen as the final determinant of IS adoption in local context adoption because of their strong support from previous studies and primary data collected.

The notion of PEOU of a system and related devices required to be used for specific taskshas been commonly associated with usability [8]. These influence the intention to use a product. Usability is also related with the attributes of a product that make it easy to use, to understand, to learn thereby making it attractive to use $[3,8]$. Whereas usability has been considered a key theme in HCI studies, we propose interactivity, active interconnectivity, and the application of simplicity concepts (supported by practitioners interviewed) for the design of human-system interfaces. In this sense effects of usability as a perception of ease of use and usefulness on attitude and intention to use _ATUI can be a determinant USBU, moderating the usability effects of a system.

\section{CONCLUSION}

A Pluralistic mixed-method study was undertaken to identify factors affecting IS adoption in local public organizations. In this article, the outcomes of the research process followed to identify the most relevant factors affecting such adoption in Ecuadorian Public Organizations was explored. We concentrated the analysis and discussion on understanding the relationship between the relevance of subjective aspects identified as direct factors that impact user behavior and possible antecedents forpriorto implementing an IS in an PEO.

A set of 50 themes proposed as candidate driver or factors affecting SISA were developed based on the results obtained either from the several stages of a mixed-method study or adopted/adapted from those proposed in prior IS/IT adoption studies. Most of the themes chosen to evaluate the impact of each driver, have been widely used in preceding studies as measurement instruments. Based on these, key propositions were developed noted between the 14 themes revised, a reflexive analysis was conducted that helps to understand HCI on government systems and to present research propositions and the hypotheses stated.

On the other hand, considering that a range of systems are used in a wide variety of settings by local public institutions, no single system designed with suggested HSI can be perceived as useful and easy to use. They should be tested with a determined group of local users. These users can represent the diversity of IS usage or its acceptance [30]. However, to ensure compatibility when testing the model, the random sample will be drawn from the same target population and use the same types of systems. By testing the proposed adapted theory, this will provide a less biased prediction of the intention of users to successfully adopt an IS in a public organisation. The sample size should be calculated based on the population related to those institutions to be surveyed.

In addition, as a part of the outcomes of the overall study, it was duly supported that no one single existing theory used in IS adoption or the extensive list of drivers proposed in such theories can be appropriate to measure SISA in local contexts. Therefore, an adapted theory developed as a hybrid model -SISA model hypothesizing the identified relationships between the selected drivers is proposed. 
It is also suggested that the SISA model needs to be further tested in a public LAT organisational environment. Therefore, future studies are recommended.

\section{ACKNOWLEDGMENTS}

Our thanks to ...

\section{REFERENCES}

[1] Dix, A.: 'Human-computer interaction': 'Encyclopedia of database systems’ (Springer, 2009), pp. 1327-1331

[2] Booth, P.: 'An Introduction to Human-Computer Interaction (Psychology Revivals)’ (Psychology Press, 2014. 2014)

[3] Davis, F.D.: 'Perceived Usefulness, Perceived Ease of Use, and User Acceptance of Information Technology', MIS Quarterly, 1989, 13, (3), pp. 319-340

[4] Davis, F.D., Bagozzi, R.P., and Warshaw, P.R.: 'User Acceptance of Computer Technology: A Comparison of Two Theoretical Models’, Management Science, 1989, 35, (8), pp. 982-1003

[5] Venkatesh, V., and Davis, F.D.: 'A Theoretical Extension of the Technology Acceptance Model', Management Science, 2000, 46, (2), pp. 186-204

[6] Venkatesh, V., Morris, M.G., Davis, G.B., and Davis, F.D.: 'User Acceptance of Information Technology: Toward a Unified View’, MIS Quarterly, 2003, 27, (3), pp. 425-478

[7] Helander, M.G.: 'Handbook of human-computer interaction' (Elsevier, 2014. 2014)

[8] Wook, M., Yusof, Z.M., and Nazri, M.Z.A.: 'The Acceptance of Educational Data Mining Technology among Students in Public Institutions of Higher Learning in Malaysia', International Journal of Future Computer and Communication, 2015, 4, (2), pp. 112

[9] Rogers, E.M.: 'Diffusion of Innovations (4th ed.)' (Free Press, 1995. 1995)

[10] 10 Tornatzky, L.G., Fleischer, M., and Chakrabarti, A.K.: 'The processes of technological innovation' (Lexington Books, 1990. 1990)

[11] DeLone, W.H., and McLean, E.R.: 'The DeLone and McLean model of information systems success: A ten-year update', Journal of Management Information Systems, 2003, 19, (4), pp. 9-30

[12] Gomez, R.: 'The Changing Field of ICTD: Growth and maturation of the field, 2000-2010', The Electronic Journal of Information Systems in Developing Countries, 2013, 58

[13] Ifinedo, P.: 'Drivers of E-Government Maturity in Two Developing Regions: Focus on Latin America and SubSaharan Africa', Journal of Information Systems and Technology Management, 2012, 9, (1), pp. 5-22

[14] Dutta, S., and Bilbao-Osorio, B.: 'The global information technology report 2012: Living in a hyperconnected world', in Editor (Ed.)^(Eds.): 'Book The global information technology report 2012: Living in a hyperconnected world' (SRO-Kundig, 2012, edn.), pp.

[15] Schneider, C.Q., and Wagemann, C.: 'Standards of Good Practice in Qualitative Comparative Analysis (QCA) and Fuzzy-Sets', Comparative Sociology, 2010, 9, (3), pp. 397418
[16] Alcivar, N.I.S., Sanzogni, L., and Houghton, L.: 'Fuzzy QCA applicability for a refined selection of drivers affecting IS adoption: The case for Ecuador. Fuzzy control \& decision making/support’, in Editor (Ed.)^(Eds.): ‘Book Fuzzy QCA applicability for a refined selection of drivers affecting IS adoption: The case for Ecuador. Fuzzy control \& decision making/support' (Institute of Electrical and Electronics Engineers Inc., 2017, edn.), pp.

[17] Creswell, J.W.: 'Qualitative inquiry \& research design: Choosing among five approaches’ (Sage, 2013. 2013)

[18] Lin, F., Fofanah, S.S., and Liang, D.: 'Assessing citizen adoption of e-Government initiatives in Gambia: A validation of the technology acceptance model in information systems success', Government Information Quarterly, 2011, 28, (2), pp. 271-279

[19] Ajzen, I.: 'The theory of planned behavior', Organizational Behavior and Human Decision Processes, 1991, 50, (2), pp. 179-211

[20] Al-Ghaith, W.A., Sanzogni, L., and Sandhu, K.: 'Factors influencing the adoption and usage of online services in Saudi Arabia', The Electronic Journal of Information Systems in Developing Countries, 2010, 40, (1), pp. 1-32

[21] Shajari, M., and Ismail, Z.: 'A comprehensive adoption model of e-government services in developing countries', in Editor (Ed.)^(Eds.): 'Book A comprehensive adoption model of e-government services in developing countries' (IEEE, 2010, edn.), pp. 548-553

[22] Alomari, M.K., Woods, P.R., and Sandhu, K.S.: 'The Deployment of E-Government in the Hashemite Kingdom of Jordan: factors in E-Government adoption', in Editor (Ed.)^(Eds.): 'Book The Deployment of E-Government in the Hashemite Kingdom of Jordan: factors in E-Government adoption' (International Association for Development of the Information Society).

[23] McClelland, D.C.: ‘The Achieving Society’ (Free Press Paperback by arrengement with D. Van Nostrand Company, Inc., 1967. 1967)

[24] Fishbein, M., and Ajzen, I.: 'Belief, attitude, intention, and behavior: An introduction to theory and research' (AddisonWesley, 1975. 1975)

[25] Wang, Y.-S., and Liao, Y.-W.: 'Assessing e-government systems success: A validation of the DeLone and McLean model of information systems success', Government information quarterly, 2008, 25, (4), pp. 717-733

[26] Erumban, A.A., and de Jong, S.B.: 'Cross-country differences in ICT adoption: A consequence of Culture?', Journal of World Business, 2006, 41, (4), pp. 302-314

[27] Moore, G.C., and Benbasat, I.: 'Development of an instrument to measure the perceptions of adopting an information technology innovation', Information systems research, 1991, 2, (3), pp. 192-222

[28] Bajaj, A., and Nidumolu, S.R.: 'A feedback model to understand information system usage', Information \& Management, 1998, 33, (4), pp. 213-224

[29] Aboelmaged, M.G.: 'Predicting e-procurement adoption in a developing country: An empirical integration of technology acceptance model and theory of planned behaviour', 
Industrial Management \& Data Systems, 2010, 110, (3), pp. 392-414 
Authors' background

\begin{tabular}{|c|c|c|c|}
\hline \multirow[b]{2}{*}{\begin{tabular}{|l|} 
Your Name \\
Nayeth \\
l. \\
Solorza \\
no \\
Alcivar
\end{tabular}} & Titilet & \begin{tabular}{|l|l|} 
Research Field \\
\end{tabular} & Personal website \\
\hline & $\begin{array}{l}\text { Full } \\
\text { Profes } \\
\text { sor }\end{array}$ & $\begin{array}{l}\text { Informati } \\
\text { on } \\
\text { System } \\
\text { Research } \\
\text { Methodol } \\
\text { ogy } \\
\mathrm{HCl}, \mathrm{HSI}\end{array}$ & \\
\hline $\begin{array}{l}\text { Luke } \\
\text { Hought } \\
\text { on }\end{array}$ & $\begin{array}{l}\text { Senior } \\
\text { Lecture } \\
r\end{array}$ & $\begin{array}{l}\text { Informati } \\
\text { on } \\
\text { Systems } \\
\text { and } \\
\text { Managem } \\
\text { ent }\end{array}$ & $\begin{array}{l}\text { https://www.griffith.edu.aul } \\
\text { business- } \\
\text { government/griffith- } \\
\text { business- } \\
\text { school/departments/depart } \\
\text { ment-international- } \\
\text { business-asian- } \\
\text { studies/staff/dr-luke- } \\
\text { houghton }\end{array}$ \\
\hline $\begin{array}{l}\text { Louis } \\
\text { Sanzog } \\
\text { ni }\end{array}$ & $\begin{array}{l}\text { Associ } \\
\text { ate } \\
\text { Profes } \\
\text { sor }\end{array}$ & & \\
\hline
\end{tabular}


*Title can be chosen from: master student, Phd candidate, assistant professor, lecture, senior lecture, associate professor, full professor 